\title{
Valorização e motivação de enfermeiros na perspectiva da humanização do trabalho nos hospitais
}

\author{
Appreciation and motivation of nurses from the perspective of work humanization in hospitals
}

Valorización y motivación de enfermeros en la perspectiva de la humanización del trabajo en hospitales

Lucila Isabel Schwertner Sprandel ${ }^{1}$, Helena Heidtmann Vaghetti ${ }^{2}$

\section{RESUMO}

Este artigo teve como objetivo identificar a percepção dos enfermeiros sobre a valorização do trabalho e a motivação profissional. Trata-se de um estudo qualitativo de caráter descritivo desenvolvido entre março e maio de 2011, com doze enfermeiros de um hospital universitário no Sul do Brasil. A coleta de dados utilizou entrevistas semiestruturadas e para a verificação dos mesmos empregou-se a análise temática. Os temas foram estabelecidos a partir dos parâmetros para a humanização do trabalho contidos na Política Nacional de Humanização da Assistência Hospitalar referentes à valorização do trabalho e motivação profissional: respeito, reconhecimento, satisfação e realização profissional. Os resultados foram analisados na perspectiva de políticas de humanização e dos estudos de Dejours, e indicaram que os enfermeiros vivenciam um conflito com os valores e compromissos do seu trabalho, o que gera a insatisfação profissional. A presença dos parâmetros estudados produz autorrealização e sua ausência é entendida como desumanização no trabalho.

Descritores: Enfermagem; Humanização da Assistência; Condições de Trabalho; Motivação; Hospitais.

\section{ABSTRACT}

This study aimed at identifying the perception of nurses regarding the appreciation of their work and professional motivation. It consists of a qualitative study of descriptive character, developed between March and May 2011, with twelve nurses from a teaching hospital in the south of Brazil. Data were collected through semi-structured interviews and verification was performed through thematic analysis. The themes were established based on the parameters for humanization of work contained in the National Policy of Hospital Care Humanization, regarding the appreciation of work and professional motivation: respect, acknowledgement, satisfaction and professional achievement. Results were analyzed under the perspective of humanization policies and the studies of Dejours, and indicated that nurses experience a conflict with the values and commitments of their work, which generates professional dissatisfaction. The presence of the studied parameters produces self-achievement and its absence is understood as work dehumanization.

Descriptors: Nursing; Humanization of Assistance; Working Conditions; Motivation; Hospitals.

\section{RESUMEN}

Se objetivó identificar la percepción de enfermeros acerca de la valorización del trabajo y la motivación profesional. Estudio cualitativo, descriptivo, desarrollado de marzo a mayo 2011 con 12 enfermeros de hospital universitario del Sur de Brasil. Datos recolectados mediante entrevistas semiestructuradas, analizadas según análisis temático. Los temas fueron establecidos a partir de los parámetros para la humanización del trabajo contenidos en la Política Nacional de Humanización de la Atención Hospitalaria referentes a la valorización del trabajo y motivación profesional: respeto, reconocimiento, satisfacción y realización profesional. Los resultados fueron analizados en la perspectiva de políticas de humanización y de los estudios de Dejours, indicando que los enfermeros experimentan un conflicto con los valores y compromisos de su trabajo, lo cual genera la insatisfacción profesional. La presencia de los parámetros estudiados produce auto-realización, y su ausencia es entendida como deshumanización del trabajo.

Descriptores: Enfermería; Humanización de la Atención; Condiciones de Trabajo; Motivación; Hospitales.

\footnotetext{
1 Enfermeira, Mestre em Enfermagem. Enfermeira da Clínica Médica do Hospital Universitário São Francisco de Paula. Pelotas, RS, Brasil. E-mail: lucilasprandel@yahoo.com.br.

${ }^{2}$ Enfermeira, Doutora em Enfermagem. Professora Adjunto da Universidade Federal do Rio Grande. Rio Grande, RS, Brasil. E-mail: vaghetti@vetorial.net.
} 


\section{INTRODUÇÃO}

No Brasil, durante muito tempo, a oferta de serviços de saúde revestiu-se de aspectos assistencialistas e caritativos, bem mais do que humanistas, quando os indivíduos eram vistos como unicamente dependentes e subordinados às ações restritivas de combate às doenças empreendidas pelo Estado. Este cenário começou a ser alterado no início dos anos 80 do século $X X$, teve sua afirmação durante a VIII Conferência Nacional de Saúde em 1986 e asseverou-se quando da promulgação da Lei 8080 em 1990, que determinou as condições para a promoção, proteção e recuperação da saúde, em especial nos itens III, IV e V do artigo $7^{0}$, onde estão explicitados alguns princípios de humanização.

Em 2001, o Ministério da Saúde criou o Programa Nacional de Humanização da Assistência Hospitalar (PNHAH), que propôs ações integradas visando mudar o padrão de assistência ao usuário nos hospitais públicos, melhorando a qualidade e a eficácia dos serviços prestados por estas instituições e acenando com a possibilidade de valorização do trabalho dos profissionais desta área(1).

O PNHAH em 2003 passou por uma revisão, e o Ministério da Saúde lançou a Política Nacional de Humanização (PNH), que estendeu a humanização do atendimento, que estava restrita aos hospitais, para toda rede do Sistema Único de Saúde (SUS) e definiu uma política, cujo objetivo central passou a ser, principalmente, os processos de gestão e de trabalho(2).

Contudo, mesmo diante das políticas voltadas à humanização, verifica-se que em muitas organizações de saúde brasileiras existe a desvalorização dos trabalhadores de saúde além da precarização das relações de trabalho e a pouca participação na gestão dos serviços. Isto, não raro, promove uma des(humanização) dos processos de trabalho dos profissionais da saúde, que, diariamente, ainda convivem com as fragilidades e dificuldades de outros seres humanos expostos às expectativas de vida, saúde, doença e morte. Este cenário conduz os trabalhadores a refletirem e agirem sobre sua relação com o trabalho, levando-os a organizarem-se ou desorganizarem-se mental, física e afetivamente para enfrentar os desafios diários ${ }^{(3)}$.

$\mathrm{O}$ PNH indica que a organização do trabalho nos hospitais deve ter por base metas discutidas coletivamente e com definição de eixos avaliativos, que avancem na implementação de contratos internos de gestão ${ }^{(5)}$. Porém, estas instituições de saúde vêm sendo caracterizados pela "rigidez hierárquica, controle, ausência de direito ou recurso das decisões superiores, forma de circulação da comunicação apenas descendente, descaso pelos aspectos humanísticos, e disciplina autoritária"(5). Com esta organização inadequada do trabalho, o equilíbrio psicossomático dos trabalhadores pode ser comprometido e os efeitos patogênicos das más condições físicas, químicas e biológicas do ambiente do trabalho potencializados(6).

Na prática, estes efeitos podem ser visualizados em um estudo recente onde, tanto na organização do trabalho quanto nas relações sócio-profissionais, os fatores da Escala de Avaliação do Contexto de Trabalho, tiveram avaliação grave e moderada à crítica, respectivamente, demonstrando modelos de gestão com discrepâncias entre o trabalho prescrito e o real, o que implica em dificuldades para o trabalhador com sobrecarga e custos humanos ${ }^{(7)}$.

Esses aspectos repercutem na (in)satisfação dos profissionais em exercerem suas atividades laborais e podem levar à desmotivação no trabalho da enfermagem ${ }^{(8)}$. Ao mesmo tempo em que a falta de motivação tem a possibilidade de causar desestruturação na organização do trabalho da enfermagem, em um esquema cíclico que se retroalimenta( ${ }^{(9)}$. No mesmo rumo, a valorização profissional encontra-se fortemente atrelada à motivação, sendo decisiva na dinâmica da mobilização subjetiva da inteligência e da personalidade no trabalho(10), o que também é encontrado em investigações que estabelecem essa correlação(11).

Em contrapartida, em alguns processos de trabalho na saúde surgem a todo momento situações novas e eventos imprevisíveis não definidos pelas prescrições da organização do trabalho. Para dar conta disso, os trabalhadores são convocados a criar e a improvisar ações ${ }^{(12)}$, o que os instigam para uma maior valorização e motivação no trabalho. Desta forma, quando o sofrimento pode ser modificado em criatividade, há uma contribuição que beneficia a identidade do trabalhador e aumenta sua resistência ao risco de desestabilização psíquica e somática; o trabalho, então, funciona como um mediador para a saúde ${ }^{(3)}$.

Mesmo com este atenuante, é urgente que sejam tomadas medidas que visem a humanização do trabalho 
da enfermagem nos hospitais ${ }^{(13-14)}$ com a participação dos trabalhadores em todo o processo, visando ao atendimento das diretrizes da $\mathrm{PNH}$ e a satisfação e motivação desses em seus processos de trabalho.

A necessidade de instigar o debate sobre a humanização do trabalho e no trabalho da enfermagem, à luz das políticas de saúde voltadas para este fim, e contribuir para a construção do conhecimento acerca da valorização e da motivação de enfermeiros, motivou-nos à realização deste estudo.

Assim, o objetivo desta investigação foi identificar como os enfermeiros percebem a valorização do trabalho e a motivação profissional no exercício de suas atividades, a partir de parâmetros para humanização do trabalho dos profissionais dispostos na $\mathrm{PNHAH}^{(4)}$, que visam avaliar realidades hospitalares e planejar ações de humanização.

Entende-se que esta pesquisa oferecerá uma reflexão crítica acerca da humanização do trabalho dos enfermeiros nos hospitais. Para além disso, poderá proporcionar uma amostra teórico-metodológica sobre a operacionalização da avaliação dos parâmetros para a humanização do trabalho dos profissionais da área da saúde, podendo ser replicada em outras realidades para promoção de ações de humanização que vão ao encontro das necessidades pontuais desses trabalhadores.

\section{MÉTODO}

Estudo descritivo de abordagem qualitativa que proporcionou uma imersão na realidade dos enfermeiros entrevistados e o conhecimento em torno da valorização e da motivação profissional no trabalho da enfermagem.

A pesquisa de campo foi desenvolvida entre os meses de março e maio de 2011 em um hospital universitário de médio porte do sul do Brasil. Os sujeitos do estudo foram enfermeiros, dos turnos da manhã e da tarde dos setores de clínica médica, clínica cirúrgica, clínica pediátrica, clínica ginecológica e obstétrica e nas duas alas de convênios e particulares da instituição, totalizando 12 sujeitos, não foram incluídos os enfermeiros do turno da noite por entendermos que o trabalho noturno possui peculiaridades que merecem atenção especial não discutidas neste estudo.

Para a coleta de dados utilizou-se uma entrevista semiestruturada, mediada por um instrumento que abordava questões relativas aos Parâmetros para a
Humanização do Trabalho dos Profissionais contidas no manual do PNHAH sobre a valorização e a motivação dos profissionais (respeito, reconhecimento, realização e satisfação no trabalho).

Para a garantia de um ambiente privativo e seguro, as entrevistas foram realizadas em salas do hospital que estavam desocupadas, no turno de trabalho dos enfermeiros, conforme a sua disponibilidade de tempo com o objetivo de não interferir na sua rotina de trabalho, sendo gravadas, transcritas imediatamente e validadas pelos sujeitos. No inicio das entrevistas os participantes eram esclarecidos quanto ao objetivo da pesquisa, momento em que era solicitada a assinatura do Termo de Consentimento Livre e Esclarecido.

Para o tratamento dos dados optou-se pela utilização da análise temática preconizada por Bardin ${ }^{(15)}$, no qual o tema é o conceito central. Na fase de préanalise foi realizada a leitura flutuante das entrevistas, visando apreender as particularidades que contribuíram para a elaboração das ideias iniciais e de orientação teórica que nortearam a organização, análise e interpretação do corpus.

Na etapa de exploração do material foi empregada a categorização apriorística, que é aquela em que o pesquisador de antemão já possui, categorias prédefinidas $^{(15)}$. Assim, foram utilizados os parâmetros para avaliação da valorização e da motivação dos profissionais de hospitais contidos na $\mathrm{PNHAH}^{(4)}$ - respeito, reconhecimento, realização e satisfação no trabalho.

Considerando que essas temáticas, de algum modo se entrelaçam e se imbricam, as três categorias derivadas do processo de análise dos dados foram se desenhando como: O reconhecimento profissional humanizando o trabalho dos enfermeiros; A satisfação e realização profissional no reflexo da humanização e O respeito na relação entre o fazer e o poder no trabalho. As mesmas foram discutidas e analisadas segundo as concepções expostas no referencial teórico, com cotejamento com estudos de diversos autores de distintas áreas do conhecimento, como administração, sociologia e saúde que abordam a temática em foco.

Para garantir o anonimato dos sujeitos, os mesmos foram identificados pela letra "E" seguida do número correspondente à ordem com que ocorreu a entrevista.

A presente investigação foi aprovada pelo Comitê de Ética em Pesquisa da Universidade Federal de Rio Grande (CEPAS) sob parecer $n^{\circ} 149 / 10$ e seguiu 
rigorosamente os preceitos éticos da pesquisa na área da saúde.

\section{RESULTADOS E DISCUSSÃO}

O respeito e o reconhecimento no trabalho da enfermagem são méritos percebidos pelas enfermeiras entrevistadas que ocorrem a partir de seu trabalho sob uma apreciação externa, que os valoriza como profissionais. Neste sentido, o respeito e o reconhecimento são a valorização, ou os valores atribuídos por outrem ao desempenho dos enfermeiros, expressando a subjetividade dos primeiros (usuários, equipe de saúde, familiares, administração do hospital e todos aqueles que convivem cotidianamente com estes enfermeiros), ao mesmo tempo em que são intuídos pelos segundos, por meio de gestos, atitudes, falas, que expressam sentimentos positivos ou negativos.

A motivação para o trabalho ocorre por meio da satisfação no trabalho e da realização profissional que são necessidades inerentes dos trabalhadores enfermeiros, mas que estão relacionadas direta ou indiretamente com o respeito e o reconhecimento profissional, em um movimento em que o conjunto "respeito e reconhecimento profissional" alimenta o conjunto "satisfação no trabalho e realização profissional". Dessa forma é que se seguiram as discussões que são apresentadas.

\section{- reconhecimento profissional humanizando o trabalho dos enfermeiros}

Ao trabalhar, o sujeito não está só satisfazendo suas necessidades de subsistência, mas está criando, transformando, se individualizando no coletivo e se coletivizando através de suas ações e relações(16). Por isso, para o enfermeiro, ser reconhecido profissionalmente por aquilo que é o seu fazer, recompensa-o pela dedicação e fornece-lhe uma identificação com o seu trabalho.

Alguns enfermeiros entrevistados percebem o reconhecimento profissional por parte de quem cuidam, seus familiares e acompanhantes, da chefia de enfermagem e dos colegas, conforme mostram as seguintes falas:

O reconhecimento vem tanto dos colegas quanto dos próprios pacientes, familiares e acompanhantes. (E3)
Eu escuto elogios do que faço, para mim está ótimo saber que as pessoas enxergam o que eu faço, é bem gratificante, como eu sou iniciante eu acho que é gratificante. (E7)

[...] Em conversas que a gente teve, com a chefia conversando sobre o trabalho que estava gostando $e$ tal[...]. (E8)

Estas formas de reconhecimento explicitadas por esses enfermeiros, ocorrem pela via do elogio ou do agradecimento e podem ser identificadas como o reconhecimento baseado em um julgamento de utilidade, proferido pelos superiores, subordinados e clientes e o reconhecimento advindo de um julgamento de estética advindo dos pares, colegas, membros da equipe ou da comunidade ${ }^{(17)}$.

Entretanto, independentemente desta categorização, o reconhecimento do trabalho destes enfermeiros contribui para a auto-realização, no sentido de realizar seu próprio potencial e de se desenvolver continuamente, levando-os a atingir um alto grau de motivação no trabalho.

Resultado semelhante também foi encontrado em um estudo ${ }^{(11)}$ em que o reconhecimento sobre o trabalho da enfermagem pelos idosos hospitalizados foi identificado como fator de motivação no trabalho naquele hospital. Assim, o reconhecimento por parte dos pacientes pode transformar o sofrimento no trabalho em prazer e realização.

Por outro lado, alguns enfermeiros, sujeitos desta pesquisa, apontaram também a falta de reconhecimento ou simples falta de reforço em atitudes positivas no trabalho como uma dificuldade que é enfrentada em busca da humanização em seu trabalho, principalmente por parte da chefia de enfermagem e da direção do hospital:

Não, porque que nunca ninguém elogiou não falou nada, se o meu trabalho é bom ou não é, o meu trabalho pra mim é de acordo como que eu acho que é certo. (E9)

Acho que ainda falta um reconhecimento, não digo específico meu, em geral para enfermeiros, eu acho que a gente não é bem reconhecido ainda. (E12)

Olha se eu sou nunca ninguém me reconheceu, nunca ninguém me elogiou parou e disse se o meu trabalho estava bom ou estava ruim. (E11) 
Pode-se apontar duas diferentes dimensões do reconhecimento, "no sentido da constatação, ou seja, reconhecimento da realidade que representa a contribuição individual, específica à organização do trabalho" e o reconhecimento "no sentido de gratidão: pela contribuição dos trabalhadores à organização do trabalho", o qual é concedido com muita parcimônia(17).

Diante do exposto pelos enfermeiros e pelo autor, observa-se que ocorre quase uma indiferença em relação ao trabalho e ao trabalhador, consistindo em uma das formas mais inumanas de convivência, indo de encontro às ideias dispostas no $\mathrm{PNHAH}^{(1)}$ e $\mathrm{PNH}^{(2)}$, que dispõem sobre a necessidade da valorização dos aspectos subjetivos voltados à humanização do trabalhador em seu processo de trabalho na saúde.

Afora este reconhecimento que está sendo enfocado até o momento, de caráter mais moral, para os sujeitos deste estudo, o reconhecimento pelo trabalho, ou melhor, a falta deste, ocorre, também, através da remuneração salarial:

\section{[...] a gente sempre acha que poderia ser mais reconhecida, melhor remunerada. (E10)}

Atualmente, os enfermeiros não possuem um teto salarial, o que faz com que muitas organizações de saúde paguem salários que estão muito aquém daquilo que os profissionais merecem diante do trabalho que executam, produzindo situações econômicas que pouco condizem com o grau e o cargo destes sujeitos. Isto se torna uma dificuldade, na medida em que, para o trabalhador, o salário contém significações "concretas (sustentar a família, pagar as melhorias da casa, pagar dívidas) e também mais abstratas na medida em que contém sonhos, fantasias e projetos de realizações possíveis", ao mesmo tempo em que pode veicular todas as significações negativas que implicam as limitações materiais que ele impõe $\mathrm{e}^{(6)}$.

A falta de reconhecimento, neste rumo, pode diminuir o potencial do trabalho, desmotivando os profissionais, e conduzindo-os à desmobilização e, consequentemente, ao sofrimento no trabalho(17).

Assim, pode-se verificar, que o reconhecimento é uma forte expectativa dos enfermeiros com relação ao seu fazer, porém raramente este é conferido na medida em que contente plenamente os profissionais, à exceção daquele advindo dos pacientes, talvez o mais original, porque é aquele em que esses profissionais se encontram no mais completo estado de autonomia, interação e resolutividade.

Portanto, este reconhecimento profissional emanado dos pacientes promove a humanização do trabalho dos enfermeiros, ao mesmo tempo em que pode potencializar a humanização da assistência que é prestada, como uma contraprestação de sentimentos. Por outro lado, isto pode acontecer de maneira reversa em relação às chefias e colegas com os quais não existe esta comunhão.

Com base no exposto, vale ressaltar, que, embora importantes, não são necessariamente as ações ditas humanizadoras que determinam um caráter humanizado ao serviço como um todo, mas a consideração aos princípios conceituais que definem a humanização como a base para toda e qualquer atividade. Este é o grande desafio: criar uma nova cultura de funcionamento institucional e de relacionamentos na qual, cotidianamente, se façam presentes os valores da humanização(5).

Há a necessidade de estabelecermos momentos de reflexão acerca do processo de trabalho, pois o trabalho em saúde resulta na assistência à saúde de seres humanos, assim, refletir e compreender esse processo é indispensável para a prestação de uma assistência de qualidade, a qual fará o trabalhador ver o produto do seu trabalho valorizado socialmente(18).

\section{A satisfação e realização profissional no reflexo da humanização}

Alguns dos enfermeiros entrevistados relatam que se sentem satisfeitos com o trabalho que desenvolvem no hospital. Dentre os motivos dessa satisfação podemos citar a afinidade com a especialidade que desenvolvem, a crença de estar fazendo um bom trabalho e de dar conta da demanda cumprindo as tarefas pré-determinadas, a visualização dos resultados positivos advindos da assistência prestada, além do bom relacionamento com a equipe de trabalho.

Satisfeita sim, porque eu consigo fazer as coisas que eu idealizei fazer, hoje eu consigo fazer, então hoje eu estou satisfeita com o que eu faço, eu vejo resultado no que eu faço, eu consigo falar com uma paciente e ver resultado naquilo que eu falei, eu consigo ver conforto nela [...]. (E7) 
Evidencia-se que os enfermeiros que assumem setores do hospital que são compatíveis com a área de sua preferência sentem-se satisfeitos com o trabalho que desenvolvem na instituição, o que vai ao encontro dos resultados de estudo similar em que os profissionais também relacionam a sua satisfação profissional com a área de atuação(19).

Outro fator a ser destacado é que o sentimento de satisfação no trabalho para os enfermeiros entrevistados está atrelado à evidência do cuidado prestado ao cliente, isto é, sentem-se satisfeitos sabendo que o seu fazer influenciou na recuperação da saúde de um indivíduo.

Neste sentido, vale reiterar que entre os dois componentes da satisfação no trabalho (em relação ao conteúdo ergonômico e ao conteúdo significativo), expostos nos resultados mencionados, "a aplicação das aptidões físicas e psicossensoriais, e o prazer que delas provem, só podem contribuir se existir de antemão um engajamento fundado sobre o prazer oriundo da relação com o conteúdo significativo da tarefa"(6), o que é o caso dos enfermeiros desta pesquisa. Desta forma, o que o cuidado significa para os sujeitos entrevistados pode potencializar a qualidade do trabalho, gerando maior satisfação.

Os mesmos motivos elencados pelos enfermeiros como desencadeadores de satisfação também contribuem com a sua realização profissional no hospital, num sentido em que eles estabelecem uma concentração agradável da atenção e da energia, criando uma espécie de fluxo:

Eu me sinto realizada por ser enfermeira e por trabalhar com pacientes [...]. (E3)

[...] De maneira geral sim, tem algumas rotinas e algumas ideias que eu estou conseguindo resolver então acho que é bem legal essa parte. (E5)

Todavia, contraditoriamente, outros enfermeiros sentem-se insatisfeitos com a carga de trabalho, o que faz com que eles não consigam atender a demanda, podendo influenciar diretamente na qualidade da assistência prestada:

Não totalmente, às vezes eu fico um pouco frustrada porque em função da demanda eu sei que eu não consigo dar a qualidade do atendimento que eu gostaria de dar, se eu tivesse mais tempo eu conseguiria, então às vezes eu não consigo conversar um pouco mais com os pacientes, fazer uma visita mais completa. (E10)

A grande demanda de trabalho no cotidiano das atividades dos enfermeiros foi apontada também como uma causa diminutiva da realização, pois faz com que a assistência e os procedimentos ocorram de uma forma mecanizada e rápida, diminuindo a qualidade do cuidado. Este fato é uma realidade importante a destacar já que o dimensionamento de enfermeiros não é seguido, ocorrendo uma excessiva demanda de trabalho para uma pessoa só, deflagrando a sensação de não cumprimento da tarefa. Assim, o tipo de organização do trabalho da enfermagem e as condições em que o mesmo é exercido produzem insatisfação, ansiedade e frustração, ocasionando a elaboração de estratégias defensivas específicas no cotidiano do trabalho. Estas são as formas adotadas e que “... contribuem para tornar aceitável aquilo que não deveria sê-lo" (10).

É importante, então, que a administração do hospital esteja atenta a estas questões, visando à humanização e minimizando as condições de sofrimento no trabalho, e se não por isso, preservando a qualidade da assistência que é prestada.

Outras causas de insatisfação profissional estão relacionadas à falta de autonomia e à dificuldade em desenvolver atividades que pertencem ao fazer do enfermeiro devido a demanda e outras atividades que o afastam da assistência:

Eu queria fazer mais, eu sou barrada, não levam adiante as minhas ideias então acaba que eu faço sempre a mesma coisa, a mesma rotina. (E9)

No cotidiano do trabalho dos enfermeiros muitos são os empecilhos e dificuldades encontradas e grande é a demanda de trabalho a realizar. Isto o faz privar-se do seu "ideal de trabalho" inundando-se de sensação de não cumprimento da tarefa e mesmo na culpabilização por muitas vezes deixar de prestar um atendimento humanizado ao seu cliente, restando-lhe uma sensação de insatisfação consigo, com o seu trabalho e o produto do mesmo:

Eu acho que o enfermeiro em geral está muito restrito, aqui a gente não tem chance de fazer, de desenvolver o papel que o enfermeiro realmente tem [...]. (E11) 
Da mesma maneira, houve relatos em que os enfermeiros mostram-se incomodados com as condições oferecidas pelo hospital para a realização do trabalho, condições essas de apoio e de incentivo:

Profissionalmente, eu me sinto, mas é por gostar do que eu faço, simplesmente por gostar, porque se for pontuar item a item, não teria como eu ser feliz com o que eu faço se eu não tenho condições adequadas de trabalho? (E11)

A ideia de que o hospital não oferece condições parciais de trabalho pode ser entendida, como uma ação específica, cujo impacto é o aparelho psíquico, ignorado nestes trabalhadores. Nestas situações, emerge um sofrimento de natureza mental, que começa quando o homem, no trabalho, já não pode fazer nenhuma modificação na sua tarefa no sentido de torná-la mais conforme às suas necessidades fisiológicas e a seus desejos psicológicos - isso é, quando a relação homemtrabalho é bloqueada(6).

Na vivência dos trabalhadores, a inadaptação entre as necessidades provenientes da estrutura mental e o conteúdo ergonômico da tarefa pode traduzir-se por uma insatisfação ou por um sofrimento, ou até mesmo por um estado de ansiedade(6).

Outras fontes de insatisfação indicadas em vários estudos são a dificuldade que os enfermeiros possuem em conciliar a gestão, a burocracia e o número de procedimentos multiplicado pelo número de pacientes, bem como a falta de tempo para um contato mais demorado com o cliente e para a escuta das suas necessidades e de sua família e, a política e administração da empresa, a supervisão técnica, o salário, a supervisão de pessoal e as condições de trabalho(19-20).

Tais colocações mostram as dificuldades enfrentadas não só pelos enfermeiros entrevistados, mas por outros que também atuam em unidades hospitalares e que contribuem para a insatisfação profissional, promovendo a rotinização das tarefas, reduzindo o espaço para construir vínculos, estimular relações e criar novas formas de cuidado que atendam as reais necessidades humanas que se apresentam em seu cotidiano $^{(20)}$.

Assim, a satisfação e insatisfação, a realização profissional ou a falta desta podem, cada qual na sua circunscrição, mesmo que tangenciadas pelo mesmo sujeito - o enfermeiro - gerar humanização ou desumanização, na medida em que promovem, de um lado, atores dinâmicos do processo de produção de saúde ${ }^{(14)}$ e, de outro, estes mesmos atores, com suas subjetividades inibidas e seus fazeres sem sentido.

Mas, acima disso, e o mais preocupante, é que podem ocorrer as chamadas relações de oposição ao trabalho, caracterizadas pelos descontentamentos permanentes sobre as condições dos hospitais, suas normas e rotinas, resultando em descaso, descompromisso, indiferença, queixas, insubordinação, falta de ética, além de causar sofrimento aos trabalhadores da saúde e, controverter a ordem que deveria ser natural, do prazer no trabalho, fazendo com que os trabalhadores da saúde se acomodem ou sucumbam frente às dificuldades operacionais do dia a $\operatorname{dia}^{(9)}$.

Então, é urgente que medidas sejam tomadas no sentido de que se faça valer o preconizado no $\mathrm{PNHAH}^{(1)}$ e $\mathrm{PNH}^{(2)}$ para que efetivamente os trabalhadores possam ter respeitados seus processos de trabalho e tenham atendidas suas necessidades para o desenvolvimento dos mesmos, pois possibilitar, criar condições para que as pessoas estejam satisfeitas e realizadas profissionalmente em seus locais de trabalho, faz parte dos valores agregados às políticas.

\section{O respeito na relação entre o fazer e o poder no trabalho}

Para que se concretize a humanização do ambiente hospitalar e da assistência à saúde é necessário que se considere o todo que constitui a organização hospitalar e não apenas o usuário. O hospital humanizado "contempla, em sua estrutura física, tecnológica, humana e administrativa a valoração e o respeito à dignidade da pessoa humana, seja ela paciente, familiar ou o próprio profissional que nele trabalha, garantindo condições para um atendimento de qualidade"(13).

Verificou-se que os enfermeiros entrevistados ao serem questionados sobre as relações de respeito no trabalho correlacionaram-nas com aquelas pessoas com quem mantém relações diretas através do seu fazer, como a equipe de enfermagem e os médicos. Estas relações entendidas como "todos os laços humanos criados pela organização do trabalho: relações com a hierarquia, com as chefias, com a supervisão, com os 
outros trabalhadores" podem ser por vezes desagradáveis e até insuportáveis ${ }^{(6)}$, havendo a necessidade da manutenção do respeito para que o trabalho se desenvolva satisfatoriamente.

Quanto à equipe, alguns enfermeiros discorrem que o respeito é mantido pela hierarquia, pelo tempo de trabalho do enfermeiro, pela imposição de normas e rotinas e pela supervisão do trabalho.

Eu acho que eu fiz ser respeitada, não que respeitada por livre e espontânea vontade das pessoas, mas com o meu trabalho e me impondo e dizendo que a coisa não é assim que funciona, eu agora estou sendo respeitada mas mais por questão de saber que eu não vou deixar as coisas acontecerem e eu tomar alguma atitude [...].(E11)

Aos enfermeiros participantes do estudo pareceu importante a relação de hierarquia com seus subordinados como forma de efetivar o seu fazer, que está atrelado à função de gerenciamento na unidade hospitalar em que atuam. Uma forma de se fazer respeitar os preceitos hierárquicos nas organizações é a promoção do medo e da ansiedade, "ter medo de ser vigiado é vigiar-se a si mesmo"(6). Nesse contexto, a organização do trabalho explora os mecanismos de defesa utilizados contra o sofrimento gerados por estes sentimentos $^{(6)}$ que podemos identificar na seguinte fala:

[...] hoje em dia as pessoas não dão muito valor para autoridade e acaba que veem como uma chata que fica cobrando, os técnicos de enfermagem fazem as coisas não por eu ser uma autoridade para eles, mas porque eu exijo muito, é uma coisa meio complicada, não é fácil. (E9)

O tempo de trabalho em um setor e a experiência profissional foram citados como contribuintes para a relação de respeito com os médicos:

Sim, eu acho que eu já tenho bastante tempo no setor, então o pessoal já me conhece, por eu ter experiência não tenho grandes problemas em conversar com os médicos, em dizer o que eu penso [...]. (E10)

A relação de respeito com a equipe de enfermagem também foi apontada por outros enfermeiros como uma forma de contribuir para trabalho:
[...] geralmente quando eu faço uma colocação a gente não tem problemas de ser ouvida, não sente desprezo nas sugestões, tem espaço para sugerir alguma coisa até reclamações, reinvindicações que a gente tem pra fazer geralmente são aceitas, nunca foi recriminado quanto a isso, respeito dos funcionários não tem problema nenhum, com a chefia também não, se a gente toma uma decisão geralmente é respeitada. (E12)

As relações de trabalho necessitam de interações baseadas em respeito e confiança para que sejam encorajados os vínculos profissionais. Nas relações humanizadoras e saudáveis admite-se que chefias ou colegas construam relações horizontais de trabalho, respeitando-se habilidades e competências individuais na construção do saber coletivo ${ }^{(14)}$.

Neste sentido, é importante que a organização hospitalar incite relações no trabalho com práticas que contribuam para que seus profissionais tenham uma convivência saudável e prazerosa no ambiente de trabalho(10). Рara isso, é necessário que sejam humanizadas as práticas de gestão e de cuidado.

Dessa forma, a valorização, com ênfase no trabalhador e respeito as suas singularidades e particularidades, oportunizando um tratamento mais humano e reconhecendo a dedicação dos trabalhadores, são fatores que contribuem para a humanização do processo de trabalho da enfermagem, estimulando o bom desempenho dos profissionais e a humanização das suas práticas.

\section{CONCLUSÃO}

Ao finalizar esta investigação identificamos que o objetivo do estudo foi alcançado e que pode contribuir no sentido de identificar a realidade da humanização do processo de trabalho dos enfermeiros na instituição hospitalar. Este conhecimento poderá colaborar no planejamento de ações que humanizem esse processo de trabalho, seguindo os princípios e diretrizes expostos pela política nacional de humanização.

Os problemas apontados mostram que os enfermeiros vivenciam um conflito com os valores e compromissos do seu trabalho, gerando a insatisfação profissional, o que torna clara a necessidade de humanizar todo 0 seu processo de trabalho, possibilitando o atendimento às necessidades humanas no seu cotidiano. 
À luz dos referenciais do PNHAH e da $\mathrm{PNH}$, considera-se a relação existente entre a valorização e a motivação profissional, pois são valores que ao fazerem parte do cotidiano de trabalho dos enfermeiros tornam o processo de trabalho mais humanizado. As relações de trabalho permeadas pelo respeito contribuem para o melhor resultado das ações da enfermagem como equipe.

O reconhecimento do trabalho exercido pelos enfermeiros estimula e mobiliza o profissional, incentivando o seu fazer. O sentimento de realização

\section{REFERÊNCIAS}

1. Ministério da Saúde. Programa Nacional de Humanização da Assistência Hospitalar [Internet]. Brasília: Ministério da Saúde; 2001 [cited 2012 dec 31]. Available from: http://bvsms.saude.gov.br/bvs/publicacoes/pnhah01.pdf. 2. Ministério da Saúde. HumanizaSUS. Política Nacional de Humanização: a humanização como eixo norteador das práticas de atenção e gestão em todas as instâncias do SUS [Internet]. Brasília: Ministério da Saúde; 2004 [cited 2012 dec 31]. Available from: http://bvsms.saude.gov.br/bvs/publicacoes/humanizasus 2004.pdf. 3. Dejours, C, Abdoucheli E, Jayet C. Psicodinâmica do trabalho: contribuições da Escola Dejouriana à análise da relação prazer, sofrimento e trabalho. São Paulo: Ed. Atlas, 1994.

4. Ministério da Saúde. Manual do Programa Nacional de Humanização da Assistência Hospitalar. Brasília: Ministério da Saúde, 2001.

5. Rios, I C. Caminhos da humanização na saúde: prática e reflexão. São Paulo: Ed. Áurea, 2009.

6. Dejours C. A loucura do trabalho. 5th ed. São Paulo: Ed. Cortez; 1992.

7. Campos JF, David HSL. Avaliação do contexto de trabalho em terapia intensiva sob o olhar da psicodinâmica do trabalho. Rev Esc Enferm USP [Internet]. 2011 [cited 2012 dec 31];45(2): 363-68. Available from: http://dx.doi.org/10.1590/S008062342011000200009 .

8. Meneghini F, Paz AA, Lautert L. Fatores ocupacionais associados aos componentes da síndrome de Burnout em trabalhadores de enfermagem. Texto Contexto Enferm. 2011 [cited 2012 dec 31];20(2): 225-33. Available from: http://dx.doi.org/10.1590/S010407072011000200002 .

9. Vaghetti HH. As perspectivas de um retrato da cultura organizacional de hospitais públicos brasileiros: uma tradução, uma bricolagem [thesis]. Florianópolis: Universidade Federal de Santa Catarina; 2008.

10. Dejours C. A banalização da injustiça social. Rio de Janeiro:

Fundação Getúlio Vargas; 2000.

11. Tavares JP, Beck CLC, Silva RM, Beuter M, Prestes FC, Rocha L. Prazer e sofrimento de trabalhadoras de enfermagem que cuidam de idosos hospitalizados. Esc. Anna Nery [Internet]. 2010 [cited 2012 dec 31];14(2): 253-9. Available from: http://dx.doi.org/10.1590/S1414-81452010000200007.

12. Ministério da Saúde. HumanizaSUS: Documento base para gestores e trabalhadores do SUS. 4th ed. Brasília: Editora do Ministério da Saúde; 2008.

13. Backes DS, Lunardi filho WD, Lunardi VL. O processo de humanização do ambiente hospitalar centrado no trabalhador. Rev Esc Enferm USP [Internet]. 2016 [cited 2012 dec 31];40(2): 221-7. Available from: http://dx.doi.org/10.1590/S0080$\underline{62342006000200010 .}$. 14. Fontana RT. Humanização no processo de trabalho em enfermagem: uma reflexão. Rev. Rene [Internet]. 2010 [cited 2012 dec 31];11(1):200-7. Available from: profissional e a satisfação no trabalho contribuem para que os enfermeiros se desenvolvam e se sintam estimulados a crescerem profissionalmente.

Neste sentido, é importante que a organização hospitalar promova possibilidades de relações de trabalho saudáveis e humanizadas, com práticas de gestão que sigam as premissas da $\mathrm{PNH}$ de valorização dos sujeitos que estão implicados no processo de produção de saúde, entre eles os usuários, os trabalhadores e os gestores e de fomento a autonomia e ao protagonismo destes sujeitos.

http://www.revistarene.ufc.br/revista/index.php/revista/article/vie $\underline{w} / 364 / p d f$.

15. Bardin, L. Análise de conteúdo. Lisboa: Ed. 70; 2009.

16. Leopardi M.T Processo de trabalho em saúde: organização e subjetividade. Florianopolis: Ed. Papa-Livros;1999.

17. Lancman S, Sznelwar LI. Christophe Dejours: Da psicopatologia à psicodinâmica do trabalho. Rio de Janeiro/Brasilia: Ed.

Fiocruz/Paralela15; 2004. 346 p.

18. Souza SS, Costa R, Shiroma LMB, Maliska ICA, Amadigi FR, Pires DEP et al. Reflexões de profissionais de saúde acerca do seu processo de trabalho. Rev. Eletr. Enf. [Internet]. 2010 [cited 2012 dec 31];12(3):449-55. Available from: http://dx.doi.org/10.5216/ree.v12i3.6855.

19. Santos MCL, Braga VAB, Fernandes AFC. Nível de satisfação dos enfermeiros com seu trabalho. Rev. enferm. UERJ [Internet]. 2008 [cited 2012 dec 31];16(1):101-5. Available from: http://www.facenf.uerj.br/v16n1/v16n1a16.pdf.

20. Traesel ES, Merlo CR. Trabalho imaterial no contexto da enfermagem hospitalar: vivências coletivas dos trabalhadores na perspectiva da Psicodinâmica do Trabalho. Rev. bras. saúde ocup. [Internet]. 2011 [cited $2012 \mathrm{dec}$ 31];36(123):40-55. Available from: http://dx.doi.org/10.1590/S0303-76572011000100005.

Artigo recebido em 31/10/2011. Aprovado para publicação em 08/05/2012. Artigo publicado em 31/12/2012. 